\title{
The Pay-What-You-Want game: What can be learned from the experimental evidence on Dictator and Trust Games?
}

\author{
Matthias GREIFF \\ Clausthal Technical University, Clausthal-Zellerfeld, Germany \\ matthias.greiff@tu-clausthal.de \\ Henrik EGBERT \\ Anhalt University of Applied Sciences, Bernburg, Germany \\ henrik.egbert@hs-anhalt.de
}

\begin{abstract}
This paper introduces the Pay-What-You-Want game which represents the interaction between a buyer and a seller in a Pay-What-You-Want (PWYW) situation. The PWYW game embeds the dictator game and the trust game as subgames. This allows us to use previous experimental studies with the dictator and the trust game to identify three factors that can influence the success of PWYW pricing in business practice: (i) social context, (ii) social information, and (iii) deservingness. Only few cases of PWYW pricing for a longer period of time have been documented. By addressing repeated games, we isolate two additional factors which are likely to contribute to successful implementations of PWYW as a long term pricing strategy. These are (iv) communication and (v) the reduction of goal conflicts. The central contribution of this study is an attempt to bridge the gap between laboratory experiments and the research on PWYW pricing, which relies largely on evidence from the field. By reviewing the relevant experiments, this study identifies factors crucial for the success of PWYW pricing and provides guidance to developing long-term applications of PWYW pricing.
\end{abstract}

Keywords: Pay-What-You-Want, PWYW Game, pricing, dictator game, trust game.

Please cite the article as follows: Greiff, M. and Egbert, H. (2017), "The Pay-What-You-Want Game: What can be learned from the experimental evidence on Dictator and Trust Games?", Management \& Marketing. Challenges for the Knowledge Society, Vol. 12, No. 1, pp. 124-139, DOI: 10.1515/mmcks2017-0008.

\section{Introduction}

For a seller it is essential to find an optimal pricing strategy for her products because the pricing mechanism determines the seller's revenue and profit. Recently, Pay-What-YouWant (PWYW) pricing has attracted considerable empirical research. PWYW pricing is a form of participative pricing (Chandran and Morwitz, 2005) in which the buyer can choose any price. In some cases, a positive minimum price is set but, mostly, buyers are free to pay any price including zero.

Research on PWYW pricing often refers to the literature on experimental economics. First, results from experimental economics show that behavior deviates from the Homo Oeconomicus model (maximization of the personal payoff). Motivations, such as fairness, inequity aversion, or reciprocity drive behavior in the laboratory, and it is argued that these motivations are likely to affect buyers' behavior in PWYW pricing (e.g., Kim, Natter and Spann, 2009; Schons et al. 2013; Kim, Kaufmann and Stegemann, 2014; Kunter 2015). Second, results from experimental economics reveal similarities between specific games investigated in the laboratory and the application of PWYW in the field (e.g., Jang and Chu, 
2012; Schmidt, Spann and Zeithammer, 2014). The two games that are mentioned most frequently are the dictator game (DG) and the trust game (TG), which we explain below.

Although many authors have mentioned the relation between a typical PWYW transaction and the dictator and the trust game, this relation has not been discussed in detail. The first goal of this paper is to introduce the PWYW Game. Using the PWYW Game, we illustrate the PWYW pricing situation as a sequential one shot game and discuss its relation to dictator and trust games. Since the DG and the TG are subgames of the PWYW Game, a closer look at the results from laboratory experiments can inform sellers about the applicability of PWYW pricing. By scrutinizing the results derived from the DG and the TG game, we expose the factors that are likely to contribute to higher prices under PWYW pricing. To outline these factors is the second goal of the paper.

From a seller's perspective, PWYW pricing can be used as a short-term marketing strategy, drawing attention to a new product (e.g., Kim, Natter and Spann, 2014), or as a long-term pricing strategy (e.g., Riener and Traxler, 2012). The literature on PWYW pricing has not fully addressed the topic of PWYW pricing as a long-term pricing strategy yet. Most studies refer to one-shot games and hence neglect repeated interactions between buyer and seller (Greiff and Egbert, 2016). Repeated games typically lead to other forms of cooperation and other equilibria as compared to one-shot games. The third goal of this paper is to outline the factors that are essential variables for the success of PWYW pricing in the long-term. The latter is particularly relevant for the application of PWYW pricing in practice. The central implication of this study is that the results from experimental economics can provide guidance to develop applications of PWYW in real business contexts.

The paper is structured as follows. The next section discusses the relation between PWYW pricing and the DG and the TG. This is done in three steps. First we provide a survey of the PWYW literature in which both games have been mentioned. Second we introduce the PWYW Game, which depicts a PWYW transaction between a seller and a single buyer. Third we describe how the DG and the TG relate to PWYW pricing. In the subsequent section, we discuss three factors which drive individual behavior in the dictator and the trust game. These factors are related to a single interaction between a buyer and a seller. The factors are (i) social context, (ii) social information, and (iii) deservingness. In reality, however, many interactions are repeated, and behavior in repeated games can differ from behavior in one-shot games. We tackle this issue in the section "PWYW as a Repeated Game" by elaborating on some results from repeated DG and TG. Based on this discussion, we identify (iv) communication and (v) the reduction of goal conflicts as factors that are likely to be relevant for the success of PWYW pricing in the long run. In the last section we conclude.

\section{Parallels between economic experiments and PWYW pricing}

Our first goal is an examination of two traditional economic experiments, the DG and the TG, sometimes also called investment game. The DG and the TG are strongly related to PWYW pricing because there is a striking similarity between the decision making process in a PWYW transaction and in the DG and the TG. However, these similarities have not been discussed yet. 
Despite their simplicity, the DG and the TG depict important aspects of PWYW pricing. And although most empirical investigations of these games have relied on student subjects and have been conducted in abstract laboratory environments, the similarities regarding the behavioral regularities in the laboratory and in PWYW pricing are remarkably strong. Hence, we argue that abstract laboratory experiments with student subjects can generate useful insights for business applications of PWYW pricing and can also be used as a guide for further research.

Table 1. Dictator and Trust Games in the PWYW Pricing Literature

\begin{tabular}{|c|c|c|}
\hline Author(s) & Experiment & Reference to DG or TG \\
\hline $\begin{array}{l}\text { Armstrong Soule } \\
\text { and Madrigal } \\
2015\end{array}$ & $\begin{array}{l}\text { Hypothetical PWYW decisions with } \\
\text { respect to concert tickets. }\end{array}$ & $\begin{array}{l}\text { Authors mention that DG and public good games } \\
\text { regularly show that subjects do not maximize } \\
\text { their payoffs. }\end{array}$ \\
\hline $\begin{array}{l}\text { Gautier and van } \\
\text { der Klaauw } 2010\end{array}$ & $\begin{array}{l}\text { In a case study authors analyze } \\
\text { voluntary payments for hotel stays } \\
\text { in a name-your-own-price context. }\end{array}$ & $\begin{array}{l}\text { Authors mention that the situation in the case } \\
\text { study has similarities with gift exchange and } \\
\text { tipping games and also with the DG and TG. } \\
\text { Results of DG, i.e. positive payments, are } \\
\text { confirmed. }\end{array}$ \\
\hline $\begin{array}{l}\text { and } \\
\text { air } 2015\end{array}$ & $\begin{array}{l}\text { In an experiment the willingness to } \\
\text { pay for a travel mug is examined } \\
\text { with respect to social interaction. }\end{array}$ & $\begin{array}{l}\text { Authors find that social interaction leads to } \\
\text { higher payments, similar to findings in DG. }\end{array}$ \\
\hline $\begin{array}{l}\text { Jang and Chu } \\
2012\end{array}$ & $\begin{array}{l}\text { In a field experiment subjects can } \\
\text { buy canned coffee. In survey } \\
\text { experiments subjects are asked for } \\
\text { their willingness to pay and the } \\
\text { price they would pay under PWYW } \\
\text { pricing. }\end{array}$ & $\begin{array}{l}\text { Authors explicitly relate PWYW to DG and } \\
\text { explanations given in the experimental } \\
\text { literature, such as fairness. They find that the } \\
\text { distribution of the ration between prices paid } \\
\text { and willingness to pay is similar to the } \\
\text { distribution of offer and endowment in DG. }\end{array}$ \\
\hline $\begin{array}{l}\text { Kim, } \mathrm{H} \\
\text { and St } \\
2014\end{array}$ & $\begin{array}{l}\text { urvey and field experiments } \\
\text { to test different influences } \\
N \text { pricing. }\end{array}$ & $\begin{array}{l}\text { Ultimatum game and DG are discussed and set in } \\
\text { the context of PWYW pricing, particularly } \\
\text { emphasized are social distance and fairness. }\end{array}$ \\
\hline $\begin{array}{l}\text { Kim, Natter, and } \\
\text { Spann 2009; } \\
2010\end{array}$ & $\begin{array}{l}\text { In field experiments payments for a } \\
\text { buffet lunch in a restaurant, cinema } \\
\text { tickets and hot beverages (2009), } \\
\text { and for restaurant meals (2010) are } \\
\text { investigated. }\end{array}$ & $\begin{array}{l}\text { DG is mentioned with respect to fairness } \\
\text { concerns and altruism (2009). } \\
\text { Ultimatum game and DG are discussed and set in } \\
\text { the context of PWYW (2010). }\end{array}$ \\
\hline $\begin{array}{l}\text { León, Noguera } \\
\text { and Tena- } \\
\text { Sánchez } \\
2012 \\
\end{array}$ & $\begin{array}{l}\text { Test of PWYW pricing in a case } \\
\text { study with holiday packages. }\end{array}$ & $\begin{array}{l}\text { The authors explicitly refer to their PWYW case } \\
\text { study as a TG with assigned roles of seller and } \\
\text { customers. They also provide a simple game- } \\
\text { theoretic model. }\end{array}$ \\
\hline $\begin{array}{l}\text { Machado and } \\
\text { Sinha } 2013\end{array}$ & $\begin{array}{l}\text { thors test PWYW in laboratory } \\
\text { periment and field experiment for } \\
\text { ferent goods. }\end{array}$ & $\begin{array}{l}\text { Authors hint that anonymity reduces altruism in } \\
\text { the DG. }\end{array}$ \\
\hline $\begin{array}{l}\text { Regner and } \\
\text { Riener } 2012 \\
\end{array}$ & $\begin{array}{l}\begin{array}{l}\text { Case study on online music } \\
\text { downloads. }\end{array} \\
\end{array}$ & $\begin{array}{l}\text { Authors accentuate anonymity in DG and relate } \\
\text { it to PWYW. }\end{array}$ \\
\hline $\begin{array}{l}\text { Santana and } \\
\text { Morwitz } 2013\end{array}$ & $\begin{array}{l}\text { Case study on payments of adoption } \\
\text { fees at animal shelter. }\end{array}$ & $\begin{array}{l}\text { Authors point out that PWYW is similar to the } \\
\text { DG. }\end{array}$ \\
\hline $\begin{array}{l}\text { Schmidt, Spann } \\
\text { and Zeithammer } \\
2014\end{array}$ & $\begin{array}{l}\text { In laboratory experiments different } \\
\text { market structures and market entry } \\
\text { decisions are tested with a varying } \\
\text { number of sellers and buyers. }\end{array}$ & $\begin{array}{l}\text { The PWYW experiments can be considered as } \\
\text { repeated TG with three trustees and a seller } \\
\text { who invests in quality. }\end{array}$ \\
\hline
\end{tabular}




\begin{tabular}{l|l|l|}
$\begin{array}{l}\text { Schons et al. } \\
2013\end{array}$ & $\begin{array}{l}\text { In a field experiment multiple } \\
\text { customer-seller transactions are } \\
\text { examined. }\end{array}$ & $\begin{array}{l}\text { Authors state that in a PWYW situation free } \\
\text { riding occurs less often than in a DG. }\end{array}$ \\
\hline
\end{tabular}

Source: Authors' review.

\section{Dictator and Trust Games in the ILiterature on PWYW pricing}

In order to illustrate that the relation between a PWYW pricing situation and the DG and the TG has not been investigated in detail yet, we briefly review the papers that refer both to the DG or the TG and to PWYW pricing. Greiff and Egbert (2016), Krzyżanowska and Tkaczyk (2016), and more recently Gerpott $(2016,2017)$ review the empirical studies on PWYW pricing between 2009 and 2016. A subset of the studies summarized by Greiff and Egbert mention the DG or the TG, and some elaborate on the link between PWYW pricing and the experimental literature. These papers are listed alphabetically in Table 1.

Most of the studies refer to findings of the DG. Particularly, the role of anonymity for payments is emphasized (e.g., Regner and Riener, 2012; Machado and Sinha, 2013) and analyzed (e.g., Jang and Chu, 2012). If social interaction is allowed in a PWYW setting, higher payments are the result (Hilbert and Suessmair, 2015). Overall, the studies either show or emphasize that in PWYW situations other regarding preferences, such as fairness considerations or altruism, and identity play a role.

With respect to the TG two studies are remarkable. Schmidt, Spann, and Zeithammer (2014) explicitly implement the TG in a laboratory experiment in order to simulate PWYW pricing situations in different market environments. Léon, Noguera, and Tena-Sánchez (2012) report a case study on selling holiday packages via PWYW pricing. They explicitly model a TG and relate the game to their case study. The results of the case study show that with respect to revenues PWYW pricing is devastating from a business perspective.

There are also some references to the ultimatum game (e.g., Kim, Natter, and Spann, 2009, 2010; Gneezy et al., 2012). They refer to altruism and fairness. Motivations which affect behavior in the ultimatum game might also affect buyers' decisions in PWYW transactions but the PWYW pricing situation does not resemble an ultimatum game. Hence, we do not elaborate on this game. Next, we introduce the PWYW Game before we discuss its relation to the DG and the TG.

\section{The PWYW Game}

The PWYW Game is a sequential game, which represents a typical PWYW interaction between a seller and a buyer. Figure 1 presents the extensive form of the game. First, the seller chooses the pricing mechanism (fixed price vs. PWYW) and product quality (high vs. low). Then, the buyer decides whether to buy or not. In case she decides to buy the good under PWYW, she also chooses price $p$.

At node 1 the seller chooses traditional pricing, e.g. a fixed price (the left part of the game tree), or PWYW pricing (the right part of the game tree). At nodes 2 and 3, the seller chooses high or low quality. (For the sake of simplicity, we assume that quality can be high or low, but in principle, quality can also be continuous.) At nodes 4 and 6 the seller chooses the price at which she intends to sell the good. At nodes 8 and 9 the buyer decides whether to buy the good or not. Nodes 5 and 7 depict the buyer's price choice if PWYW pricing is chosen. 
The first payoff refers to the seller. For one unit of a good the payoff is 'price being paid' minus costs. The payoff is zero if the buyer does not purchase and it is negative if price being paid does not cover costs. The second payoff refers to the buyer. It is determined as her willingness to pay (WTP) minus the price being paid.

Figure 1. Sequential Pricing and Buying Decision: The PWYW Game

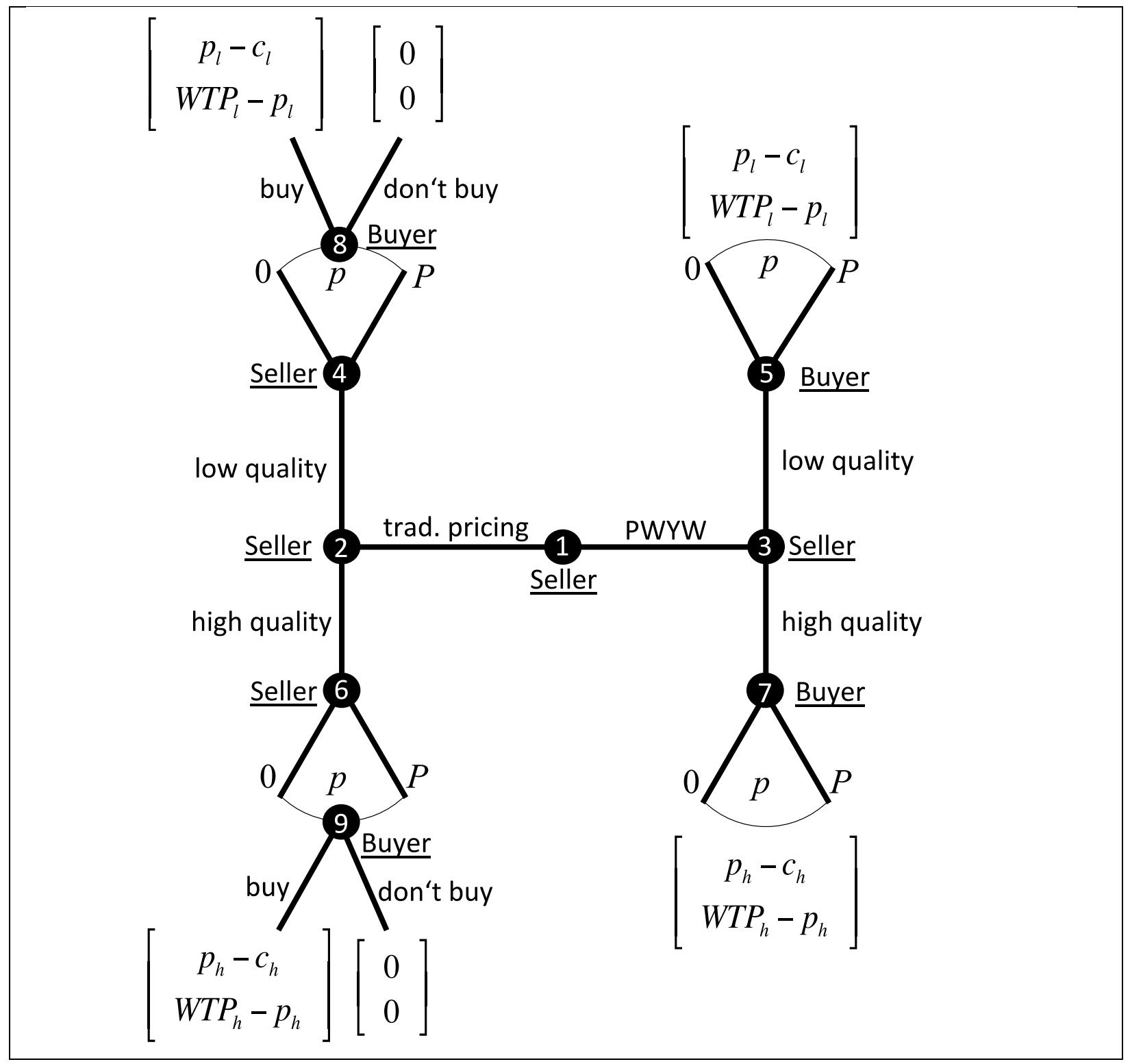

Source: Authors.

The Dictator Game (DG) and the Trust Game (TG)

In the DG (Kahneman, Knetsch, and Thaler, 1986; Forsythe et al., 1994) there are two players, dictator and receiver. The dictator has the power to allocate a given endowment between herself and a receiver. The receiver has no choice but to accept the dictator's offer. 
Game theory predicts that dictators, who want to maximize their personal payoffs, keep their endowment completely and transfer nothing to the receiver.

General results: Results reveal that the majority of dictators do not maximize their payoffs. Instead, most dictators transfer positive amounts to recipients (for surveys see Camerer, 2003, chap. 2; Cárdenas and Carpenter, 2008; and Engel, 2011 for a metaanalysis). The average transfer is 20 percent of the endowment (Camerer, 2003, 56). Since in an anonymous one-shot game strategic concerns are absent, the common interpretation of dictators' behavior is that dictators have other-regarding preferences. They are altruistic and care about recipients' incomes.

Application to PWYW: The DG is a highly stylized version of a buyer's decision about how much to pay in a PWYW mechanism. In the PWYW Game (Figure 1), the sub-games starting at nodes 5 and 7 are dictator games. The buyer's (seller's) role in the PWYW Game corresponds to the dictator's (receiver's) role in the DG. The buyer, who has received the product, decides about how much to pay for it. Hence, the dictator's transfer corresponds to the price paid. The amount of money available to the buyer corresponds to the dictator's endowment.

In the DG, a positive transfer implies a positive income for the receiver. Applied to PWYW this, however, does not mean that a seller makes a profit if the buyer pays a positive price. Only if the price paid is above the seller's marginal cost $(p>c)$, the seller makes positive profit. If $p<c$, the seller incurs a loss. Indeed, in contrast to the standard DG where the minimal payoff of the receiver is zero, in a PWYW situation the payoff for the receiver may be negative in case a buyer pays less than the marginal cost.

The TG was introduced by Berg, Dickhaut, and McCabe (1995). Two players, a trustor and a trustee interact. Player 1 , the trustor, has endowment $X$ and chooses to invest $T \leq X$. $T$ earns an interest at the rate $r$ (exogenously given). Player 2 , the trustee, receives the investment plus interest $T+r T=(1+r) T$. Next, she decides how much to return to the trustor. Let $Y$ denote the amount the trustee keeps for herself, so that she returns $(1+r) T$ - $Y$. Payoffs are $X+r T-Y$ for the trustor and $Y$ for the trustee.

Assuming that both players maximize their monetary payoffs, the trustee returns nothing. This will be anticipated by the trustor, who invests nothing. This subgame perfect equilibrium is inefficient.

General results: In Berg et al.'s experiment trustors and trustees were endowed with $X=10$. Investments were exogenously tripled by the experimenter, $r=2$. On average, trustees invested about half of their endowment. Trustors returned, on average, slightly less than the invested amount. If we take a closer look at the trustees' decisions in experiments, we find that about half of the trustees returned zero or one $((1+r) T-Y=0$ or $(1+r) T-Y=1)$. This implies that the other half of trustees returned more than the amount invested by the trustors $((1+r) T-Y>T)$. Similar results have been obtained in other TG experiments (see, e.g., the survey of Bolle, 1998; Ortmann, Fitzgerald and Boeing, 2000; Camerer, 2003, chap. 2.7).

The typical interpretation is that the trustor's decision is a signal of trust and the trustee's decision is a signal of trustworthiness. Based on this interpretation the typical results about trustees' behavior can be rephrased. About half of the trustees betray the trustors' trustworthiness and return (almost) nothing, while the other half of the trustees honor trust by returning more than the investment, i.e., by choosing $r T>Y$. 
The decision to honor trust can be motivated by positive reciprocity, i.e., a propensity to reward friendly behavior (see Albert et al., 2007; for a survey Fehr and Gächter, 2000). As in the DG, altruism can also be a motivation. However, the observation that the amount returned by trustees in the TG exceeds the amount given by dictators in the DG, makes it likely that altruism is not the only explanation.

Application to PWYW: How does the TG relate to the PWYW Game? In the PWYW Game (Figure 1), the subgame starting at node 3 is a TG in which player 1 is the seller and player 2 is the buyer. In this subgame, the seller chooses the quality of the product before the buyer agrees on a transaction and chooses a price. Assume that the buyer's utility is given by the difference between her willingness-to-pay $W T P$ and the price $p$. Hence, her utility is given by $u=W T P-p=(1+r) T-Y$ with $W T P=(1+r) T$ and $Y=p$.

A possible interpretation is that $T$ reflects the seller's marginal cost, which is increasing in quality $\left(c_{l}<c_{h}\right)$. $X$ corresponds to the cost of producing an additional unit of the good in the highest quality. Higher choices of quality result in better products, so that $W T P=(1+r) T$ increases in quality $\left(W T P_{l}<W T P_{h}\right)$. In the standard TG, $r>0$, hence $(1+r) T>$ $T$. This implies that a buyer's WTP always exceeds the seller's cost. However, for players with a WTP below marginal cost, the TG is not appropriate. A modified version of the TG, which we sketch in the next paragraph, can be used to analyze this case.

One way to modify the TG and to include buyers whose WTP is below the seller's cost, is to relax the assumption that $r$ is positive. The modified TG with $r<0$ depicts a transaction of a buyer and a seller with $W T P<c$. In such a game, either the buyer or the seller incurs a loss if a transaction takes place, regardless of the price. The seller makes a loss if $p<W T P$ and the buyer realizes a loss if $p>W T P$.

In the PWYW Game, the seller is at risk of making a loss. A loss would occur if the price paid is below the seller's cost, $p<c$. If the price that a buyer is willing to pay is below the seller's cost, as it is likely to be the case in the modified TG where $W T P<c$, the buyer might refuse to buy the good. Fairness or image concerns might prevent these buyers from buying at all (see Gneezy et al., 2012 for empirical evidence). This outside option of refusing to buy the good is possible in PWYW transactions but not included in the DG, the TG and the PWYW game, as discussed in this paper. A detailed discussion of sorting and partner choice is beyond the scope of this paper (for a discussion of DG and TG with sorting see Slonim and Garbarino, 2008; or Lazear, Malmendier and Weber, 2012).

\section{Factors driving behavior}

The DG and the TG are theoretical models depicting various aspects of PWYW transactions. They help to identify variables that have also an influence on similar decisions outside the laboratory. For the DG, Camerer (2003), Cárdenas and Carpenter (2008), and Engel (2011) list a considerable number of explanatory variables that affect transfers. Camerer (2003) also records a large number of explanatory variables that affect behavior in the TG. Among these variables are (i) social context, (ii) social information, and (iii) deservingness. These three variables essentially affect behavior in the DG and the TG and are also likely to be of relevance in PWYW pricing. Next, we examine these three variables. 


\section{Social context}

Social context includes features such as anonymity, social distance, and communication. Social context matters in PWYW because the strength of subjects' social preferences varies with the context. Several experiments have shown that behavior in the DG and TG is highly sensitive to the social context in which the decision is made. Three explanations are at hand. Firstly, in the DG social context determines the relation between the dictator and the experimenter. For instance, Hoffman et al. $(1994,1996)$, Franzen and Pointner $(2012$ show that increasing the dictator's anonymity vis-à-vis the experimenter reduces transfers. This implies that if anonymity is not given and the experimenter is able to observe transfers, positive transfers might be driven by social image concerns, i.e., the desire to appear fair to the experimenter. Although there is no experimenter in PWYW transactions, third parties, like fellow buyers, neighbors, or citizens, might observe buyers' payment. Hence, the degree of anonymity could influence buyers' behavior.

Secondly, social context determines the relation between both players (dictator and recipient in the DG, trustor and trustee in the TG). Bohnet and Frey (1999) systematically vary anonymity between the dictator and the recipient and show that loosening anonymity (by allowing for silent identification or communication) increases transfers. If subjects are allowed to communicate before the decisions are made, dictators are more generous (Bohnet and Frey 1999). For the TG, Ben-Ner, Putterman, and Ren (2011) argue that communication results in non-binding agreements and leads to an increase in trusting behavior and trustworthiness.

Closely related to the effect of communication is the effect of social distance. Several TG experiments (e.g., Fershtman and Gneezy, 2001; Glaeser et al., 2000 for related survey evidence) find that trust and trustworthiness is inversely related to social distance. The higher the social distance, the lower the trust and trustworthiness is. Social distance can be considered to be low if both players are of the same nationality or the same ethnicity. Bouckaert and Dhaene (2004) conducted a TG with Turkish and Belgian businessmen from Ghent and found no effect of ethnic origin. A possible explanation for this is that all subjects share the same identity, namely being businessman from Ghent. Possibly, the shared identity as businessman from Ghent dominated the effect of differences in ethnicity.

A possible explanation for the effect of social context on behavior is that otherregarding preferences or social image concerns become stronger if anonymity if loosened, or, if social distance decreases (see also Andreoni and Bernheim, 2009). This is of relevance for PWYW, especially if the goods are services, because most transactions are personal interactions in which there are ample opportunities for communication between buyer and seller (see Kim, Natter and Spann, 2009). Regner and Riener (2012) also show that voluntary payment for music downloads increases when anonymity is reduced, i.e. when the name and email-address of the buyer is revealed to the artist.

Thirdly, social context determines how players perceive the relation between action and outcome. For instance, Dana, Weber, and Kuang (2007) show that dictators choose smaller transfers if moral excuses for selfish behavior are available. In one treatment, dictators choose between a fair $(5,5)$ and an unfair allocation $(6,1)$, but if they do not make a choice within an unspecified time limit (between 0 and 10 seconds), one allocation is randomly selected. The receiver is not informed about whether the decision was made by the dictator or randomly. Compared to a control treatment without moral excuses, dictators 
chose the unfair allocation more frequently, possibly because the design of the experiment allowed dictators to be selfish without appearing unfair. Dana et al. argue that this behavior is motivated by social image and self image concerns. This implies that even in double-blind experiments, where the experimenter cannot observe transfers, image concerns affect behavior because dictators reflect on their own behavior (i.e., self image concerns) and recipients observe dictators' transfers (i.e., social image concerns).

These findings seem to be relevant for PWYW situations. In most PWYW transactions, sellers have some control over the social context in which the transaction takes place. If we assume that a buyer's behavior is driven by self image concerns, then the buyer's perception of the goal of the PWYW transaction is crucial. For instance, if a buyer expects that a seller uses PWYW pricing as a promotional tool with the goal of bringing attention to the good, the buyer may conclude that paying nothing is fair. The good may be perceived as a free sample offer. However, if a buyer expects that the seller uses PWYW pricing as a long-term business model, she might conclude that paying nothing is unfair.

\section{Social information}

By social information we mean information about the behavior of other players who do not directly affect the outcome of the game. In the DG such players can be dictators who have played the game before. Cason and Mui (1998) and Iriberri and Rey-Biel (2011) illustrate that social information affects dictators' behavior. In both experiments, the DG is played twice. In each game, dictators face different opponents. After the first game, dictators are informed about other dictators' behavior in the first game, and this information affects their behavior in the second game. It is plausible that social information influences behavior because dictators experience discomfort when disagreeing with the majority (a preference for conformity), or because dictators are uncertain about the appropriate behavior.

Not only in the DG but also in the TG behavior is sensitive to social information. Information about the choices of trustors and trustees, who have already played the game, can signal the existence of a norm. Berg et al. $(1995,132)$ argue that the salience of the internalized norm increases when subjects have already played the game. Results show that when social information is provided, trustworthiness increases (e.g., Berg et al., 1995; Ortmann, Fitzgerald and Boeing, 2000).

In a PWYW context this is important since it is possible that buyers observe prices paid by others (e.g., Racherla, Babb and Keith, 2011). Furthermore, sellers can provide the information about prices which had been paid in the past, or they can inform about different types of reference prices. For example, Jang and Chu (2012) demonstrate that information about production cost and reference prices influences buyers' behavior. Krawczyk, Kukla-Gryz and Tyrowicz (2015) show that for e-books, prices chosen by buyers are strongly influenced by average prices. Johnson and Cui (2013) illustrate that prices paid by buyers are influenced by the available information (information about minimum, maximum or suggested prices), and that the seller's revenue is largest when no information is provided. This is confirmed by Thomas and Gierl (2014), who find that buyers' selfreported WTP is lower if a minimum price is provided compared to the case in which no information is provided.

What are the reasons for the negative effect of information - in particular, the information about minimum prices - on buyers' prices? A possible explanation refers to self 
image concerns and costs of control. If buyers have incomplete information about their own fairness, they can self-signal their fairness by paying positive prices. However, if a minimum price is set by the seller, the signal is weaker. In addition, a minimum price might be perceived as a signal of distrust, to which buyers could react by paying lower prices (see Falk and Kosfeld, 2006).

\section{Deservingness}

Deservingness relates to the size and source of the dictator's endowment. Ruffle (1998) studies DG in which the size of the dictator's endowment is determined by the receiver. Receivers are engaged in an ability task (general knowledge and skill-testing questions) and receivers' performance determines the dictators' endowments. The dictator is endowed with $\$ 10$ in the case the recipient she is matched with belongs to a group of recipients whose performance in the ability task is above the mean. This modification introduces a legitimate claim on the side of receivers: a receiver who exerted effort to increase the dictator's endowment should be rewarded for her effort. Results show that dictators who received their endowments because receivers exerted effort, also choose higher transfers compared to dictators who received the same endowment based on a coin toss.

This result is of relevance for PWYW because the seller, who produced the good or service and incurred the cost, has a legitimate claim on receiving a positive price. It is not unreasonable that buyers recognize this and hence pay positive prices. Assuming that the seller's cost is related to the quality of the good, and that a buyer's WTP increases with quality, sellers of high quality goods deserve higher prices. Support for this claim can be found in Jang and Chu (2012), who find that buyers are willing to pay more when informed about costs.

In this section we discussed how behavior in the DG and TG depend on three variables, social context, social information and deservingness. Knowledge of how these variables affect behavior is of crucial importance for PWYW pricing because these variables can be affected by the seller. By manipulating social context, social information and deservingness, sellers can influence prices that buyers will pay in non-repeated transactions. In the next section, we discuss whether this section's results carry over to repeated games, which can be used to model repeated PWYW interactions between a buyer and a seller.

\section{PWYW as a repeated game}

So far, we have focused our discussion on one-shot games. Each game represents a single transaction between a buyer and a seller. Given that many buyer-seller interactions are repeated, one might ask whether the results from the previous section are valid also for repeated interactions.

Repeated games are more complex. With the number of repetitions, the action space grows because players can condition their behavior in a specific period on the outcome of previous periods. For finitely repeated games, the subgame-perfect equilibrium can be found by backward induction. In the equilibrium of the finitely repeated DG and TG, players play the equilibrium of stage game in each period. In infinitely and indefinitely repeated games backward induction cannot be applied, either because there is no last period, or 
because the last period is unknown a priori. In addition to the finitely repeated games' equilibria, new equilibria become possible. In these newly emerging equilibria, players cooperate in a sequence of actions and deviation is punished in future periods.

An example could be a situation where the seller offers the good under a PWYW pricing mechanism only if the buyer's payment covers costs. If the buyer pays less, the seller chooses another pricing mechanism. If buyer and seller put sufficient weight on future interactions, an equilibrium in the indefinitely repeated game is to pay under PWYW pricing a price that covers costs. One can conclude from this example that in a repeated game, behavior might be driven by motives other than the ones in one-shot games. Such motives are strategic since they are linked to expected benefits of repeated interaction in the future. On the one hand, sellers might take action to create customer loyalty (invest in product quality or atmosphere or advertising) because they expect higher revenues in the future. On the other hand, buyers might pay prices above costs to keep the seller in business (Mak et al., 2015).

With respect to strategic motives we formulate two questions. (1) Is behavior constant across several repetitions of the same game? (2) How does behavior change when new information is revealed through a repeated interaction?

Regarding constant behavior, the question is how past behavior affects future behavior. Several studies find evidence for the effect of moral licensing. Good actions tend to be followed by bad actions and vice versa so that a balance is achieved. Licensing is driven by conflicting goals (Mullen and Monin, 2016). In the DG, for example, the goal to be pro-social on the one hand and the goal to maximize one's own payoff on the other hand, stand in conflict to each other. Evidence in support of moral licensing can be found on Brañas-Garza et al. (2013). They study a finitely repeated DG in which in each period dictators are matched with a new recipient and find that subjects who behaved nicely (selfish) in one period tend to behave selfish (nicely) in the subsequent period.

However, there is also evidence showing to the opposite results and more in favor of constant individual behavior. Building on the theory of self-perception, Gneezy et al. (2012) argue that individual behavior depends of self-perception, and that self-perception is influenced by behavior in the past. Gneezy et al. (2012) find that costly pro-social behavior (in their case making a costly donation) affects individual self-perception so that individuals, who engage in costly pro-social behavior, show subsequent pro-social behavior.

In the case that individuals have a desire to conform to a social norm but are uncertain about the norm, new information can affect behavior. For instance, information about others' behavior can function as a signal about the norm (as already mentioned above). Cason and Mui (1998) present evidence from a repeated DG where dictators' generosity decreases if subjects are confronted with irrelevant information but does not decrease if subjects receive relevant information. Applied to PWYW, this finding suggests that sellers can influence the success of PWYW pricing by providing information in order to establish and communicate a social norm about the appropriate price. Such information refers to, for instance, (1) product quality, (2) average prices paid by other buyers (see the discussion on reference prices), (3) the nature of the PWYW pricing itself (short-term promotional campaign vs. long-term business model), or (4) possible consequences for buyers if prices paid are too low (seller avoids this pricing mechanism or goes out of business).

Vol. 12, No. 1, Spring, pp. 124-139, ISSN 1842-0206 | Management \& Marketing. Challenges for the Knowledge Society 
Engle-Warnick and Slonim (2004) study repeated trust games. In their experiment subjects play several repeated TG. Within each repeated TG the same two subjects interact repeatedly (partner matching), but between repeated games subjects change. In treatment 1 the repeated game is a TG which is played five times, in treatment 2 the repeated game is a TG which after each period continues with probability 0.8 . In treatment 1 , subjects know that period 5 is the last period and can apply backward induction. In treatment 2 , subjects never know if the current period will be the last period of the game, hence, they cannot apply backward induction.

Engle-Warnick and Slonim (2004) find that in both treatments, trust decreases as the trust game is repeated with the same partner, and that trust is reset at high levels when a new game with a new partner begins. Regarding the trustor's behavior in the sequence of repeated games, there is no difference in trust across treatments. For experienced subjects, however, trust decreases in treatment 1 but not in treatment 2. Overall, the results show that in repeated TG, trust remains high if the concern for the future is important.

Results from repeated games highlight the importance of communication and the reduction of goal conflicts for the long-term success of PWYW pricing. This does not in any sense imply that the three factors that we identified in section 3 , are not relevant in the long-term. Rather it is the case that communication and the reduction of goal conflicts - in addition to social context, social information, and deservingness - influence behavior in repeated games. Partly, short-term and long-term consideration reinforce each other.

\section{Conclusion}

Given the fast growing literature on PWYW pricing and the vague references to the DG and the TG within this literature, we introduce the PWYW Game to analyze how PWYW pricing is related to the DG and the TG. The PWYW Game emphasizes the formal game-theoretical structure behind PWYW pricing and highlights the similarity between PWYW pricing, the DG, and the TG. We think that a closer look at the results from laboratory experiments on the DG and the TG can further refine and elaborate the existing literature on PWYW pricing. Based on the similarity between the dictator's decisions in the DG, the trustor's decision in the TG, and the buyer's decision in a typical PWYW transaction, we argue that the results from DG and TG experiments can generate useful insights for applications of PWYW pricing. More specifically, we consider such an analysis as necessary in order to identify those variables that can help a seller to make PWYW pricing a feasible pricing strategy, both in the short and in the long run.

Since the DG and the TG are the workhorses of experimental economics, a number of experiments show how specific variables affect individual decisions. Given the similarities between a PWYW transaction and these games, which become apparent in the PWYW Game, we identify the factors that are relevant in DG and TG and can also be relevant for decisions in PWYW pricing situations. Particularly, we identify and discuss three factors which are likely to affect behavior in the DG, the TG, and buyers' choices of how much to pay in a PWYW transaction. These three factors - (i) social context, (ii) social information, and (iii) deservingness - are most likely to affect a seller's revenue in the short-term.

In repeated interactions, (iv) communication and (v) the reduction of goal conflicts lead to more pro-social behavior and these factors are most likely to contribute to the 
success of PWYW pricing. In sum, the experimental results discussed in this paper show how abstract laboratory experiments can be used as a guidance in the search for an optimal pricing strategy.

Closely related to the results from repeated experiments is the marketing literature on sequential choice, which discusses how past experiences affect choices (see Huber, Goldsmith, and Mogilner 2008). There are conceptual differences between both approaches. While the experimental economics literature is concerned with testing gametheoretical predictions in abstract laboratory settings, the sequential choice literature is concerned with the psychological mechanisms that affect behavior. Nonetheless, we believe that both approaches can complement each other in order to derive business policies for the success of PWYW pricing and other participative pricing models.

\section{References}

Andreoni, J. and Bernheim, D.B. (2009), "Social Image and the 50-50 Norm: A Theoretical and Experimental Analysis of Audience Effects", Econometrica, Vol. 77, No. 5, pp. 1607-1636.

Albert, M., Güth, W., Kirchler, E. and Maciejovsky, B. (2007), "Are we nice(r) to nice(r) people? An experimental analysis", Experimental Economics, Vol. 10, pp. 53-69.

Armstrong S., Catherine, A. and Madrigal, R. (2015), "Anchors and norms in anonymous pay-what-you-want pricing contexts", Journal of Behavioral and Experimental Economics, Vol. 57, pp. 167-175.

Ben-Ner, A., Putterman, L. and Ren, T. (2011), "Lavish returns on cheap talk: Two-way communication in trust games", The Journal of Socio-Economics, Vol. 40, No. 1, pp. 113.

Berg, J., Dickhaut, J. and McCabe, J. (1995), "Trust, reciprocity, and social history", Games and Economic Behavior, Vol. 10, No. 1, pp. 122-142.

Bohnet, I. and Frey, B.S. (1999), "The sound of silence in prisoner's dilemma and dictator games", Journal of Economic Behavior \& Organization, Vol. 38, No. 1, pp. 43-57.

Bolle, F. (1998), "Rewarding trust: An experimental study", Theory and Decision, Vol. 45, No. 1, pp. 83-98.

Bouckaert, J. and Dhaene, G. (2004), "Inter-ethnic trust and reciprocity: results of an experiment with small businessmen", European Journal of Political Economy, Vol. 20, No. 4, pp. 869-886.

Brañas-Garza et al. (2013), "Moral cleansing and moral licensing: experimental evidence", Economics and Philosophy, Vol. 29, No. 2, pp. 199-212.

Camerer, C.F. (2003), Behavioral game theory: experiments in strategic interaction, Princeton University Press, Princeton.

Cárdenas, J.C. and Carpenter, J. (2008), “Behavioural development economics: Lessons from field labs in the developing world", The Journal of Development Studies, Vol. 44, No. 3, pp. 311-338.

Cason, T.N. and Mui, V.L. (1998), "Social influence in the sequential dictator game", Journal of Mathematical Psychology, Vol. 42, No. 2-3, pp. 248-265. 
Chandran, S. and Morwitz, V.G. (2005), "Effects of participative pricing on consumers' cognitions and actions: A goal theoretic perspective", Journal of Consumer Research, Vol. 32, No. 2, pp. 249-259.

Collett, J.L. and Childs, E. (2011), "Minding the gap: Meaning, affect, and the potential shortcomings of vignettes", Social Science Research, Vol. 40, No. 2, pp. 513-522.

Dana, J., Weber, R.A. and Kuang, J.X. (2007), "Exploiting moral wiggle room: Experiments demonstrating an illusory preference for fairness", Economic Theory, Vol. 33, No. 1, pp. 67-80.

Engel, C. (2011), “Dictator games: A meta study”, Experimental Economics, Vol. 14, No. 4, pp. 583-610.

Engle-Warnick, J. and Slonim, R.L. (2004), "The evolution of strategies in repeated trust games", Journal of Economic Behavior \& Organization, Vol. 55, No. 4, pp. 553-573.

Falk, A. and Kosfeld, M. (2006), "The hidden costs of control", The American Economic Review, Vol. 96, No. 5, pp. 1611-1630.

Fehr, E. and Gächter, S. (2000), "Fairness and retaliation: The economics of reciprocity", The Journal of Economic Perspectives, Vol. 14, No. 3, pp. 159-181.

Fershtman, C. and Gneezy, U. (2001), "Discrimination in a segmented society: An experimental approach", The Quarterly Journal of Economics, Vol. 116, No. 1, pp. 351377.

Forsythe, R., Horowitz, J.L., Savin, N.E. and Sefton, M. (1994), "Fairness in simple bargaining experiments", Games and Economic Behavior, Vol. 6, No. 3, pp. 347-369.

Franzen, A. and Pointner, S. (2012), "anonymity in the dictator game revisited", Journal of Economic Behavior \& Organization, Vol. 81, No. 1, pp. 74-81.

Gautier, P.A. and van der Klaauw, B. (2012), "Selection in a field experiment with voluntary participation", Journal of Applied Econometrics, Vol. 27, pp. 63-84.

Gerpott, T.J. (2017), "Pay-what-you-want pricing: An integrative review of the empirical research literature", Management Science Letters, Vol. 7, pp. 35-62.

Gerpott, T.J. (2016), "A review of the empirical literature on pay-what-you-want price setting", Management \& Marketing. Challenges for the Knowledge Society, Vol. 11, No. 4, pp. 566-696.

Glaeser, E.L., Laibson, D.I., Scheinkman, J.A. and Soutter, C.L. (2000), "Measuring trust”, The Quarterly Journal of Economics, Vol. 115, No. 3, pp. 811-846.

Gneezy, A., Gneezy, U., Riener, G. and Nelson, L.D. (2012), "Pay-what-you-want, identity, and self-signaling in markets", Proceedings of the Royal Academy of Sciences, Vol. 109, No. 19, pp. 7236-7240.

Greiff, M. and Egbert, H. (2016), "A survey of the empirical evidence on PWYW pricing", Bulgarian Economic Papers, BEP 02-2016, Sofia.

Hilbert, L.P. and Suessmair, A. (2015), "The effects of social interaction and social norm compliance in pay-what-you-want situations", American Journal of Industrial and Business Management, Vol. 5, pp. 548-556.

Hoffman, E., McCabe, K., Shachat, K., Smith, V.L. (1994), "Preferences, property rights, and anonymity in bargaining games", Games and Economic Behavior, Vol. 7, No. 3, pp. 346-380. 
Hoffman, E., McCabe, K. and Smith, V.L. (1996), "Social distance and other-regarding behavior in dictator games", The American Economic Review, Vol. 86, No.3, pp. 653660.

Huber, J., Goldsmith, K. and Mogilner, C. (2008), "Reinforcement versus balance response in sequential choice”, Marketing Letters, Vol. 19, No. 3-4, pp. 229-239.

Iriberri, N. and Rey-Biel, P. (2011), "The role of role uncertainty in modified dictator games", Experimental Economics, Vol. 14, No. 2, pp. 160-180.

Jang, H, and Chu, W. (2012), "Are consumers acting fairly toward companies? an examination of pay-what-you-want pricing", Journal of Macromarketing, Vol. 32, No. 4, pp. 348-360.

Johnson, J.W. and Peng Cui, A. (2013), "To influence or not to influence: external reference price strategies in pay-what-you-want pricing", Journal of Business Research, Vol. 66, No. 2, pp. 275-281.

Kahneman, D., Knetsch, J.L. and Thaler, R. (1986), "Fairness as a constraint on profit seeking: Entitlements in the market", The American Economic Review, Vol. 76, No. 4, pp. 728-741.

Kim, J.Y., Kaufmann, K. and Stegemann, M. (2014), "The impact of buyer-seller relationships and reference prices on the effectiveness of the pay what you want pricing mechanism", Marketing Letters, Vol. 25, pp. 409-423.

Kim, J.Y., Natter, M. and Spann, M. (2009), "Pay what you want: A new participative pricing mechanism", Journal of Marketing, Vol. 73, No. 1, pp. 44-58.

Kim, J.Y., Natter, M. and Spann, M. (2010), "Pay what you want: Relevance and consumer behavior", Zeitschrift für Betriebswirtschaft, Vol. 80, No. 2, pp. 147-169.

Kim, J.Y., Natter, M. and Spann, M. (2014), "Sampling, discounts or pay-what-you-want: Two field experiments", International Journal of Research in Marketing, Vol. 31, No. 3, pp. 327-334.

Krawczyk, M., Kukla-Gryz, A. and Tyrowicz, J. (2015), "Pushed by the crowd or pulled by the leaders", Working Paper No. 25/2015 (173), Faculty of Economic Sciences, University of Warsaw.

Krzyżanowska, M. and Tkaczyk, J. (2016), "Pay-what-you-want as a participative pricing mechanism: Meta-analysis of development and knowledge dissemination", International Journal of Management Cases, Vol. 18, No. 2, pp. 21-38.

Kunter, M. (2015), "exploring the pay-what-you-want payment motivation", Journal of Business Research, Vol. 68, No. 1, pp. 2347-2357.

Lazear, E.P., Malmendier, U. and Weber, R.A. (2012), "Sorting in experiments with application to social preferences", American Economic Journal: Applied Economics, Vol. 4, No. 1, pp. 136-163.

Léon, F.J., Noguera, J.A. and Tena-Sánchez, J. (2012), “How much would you like to pay? Trust, reciprocity and prosocial motivations in El trato", Social Science Information, Vol. 51, No. 3, pp. 389-417.

Machado, F. and Sinha, R.K. (2013), “The viability of pay what you want pricing”, Working Paper.

Mak, V., Zwick, R., Rao, A. and Pattaratanakun, J.A. (2015), “'Pay what you want' as threshold public good provision", Organizational Behavior and Human Decision Processes, Vol. 127, pp. 30-43. 
Mullen, E. and Monin, B. (2016), “Consistency versus licensing effects of past moral behavior", Annual Review of Psychology, Vol. 67, pp. 363-385.

Ortmann, A., Fitzgerald, J. and Boeing, C. (2000), "Trust, reciprocity, and social history: A reexamination", Experimental Economics, Vol. 3, No. 1, pp. 81-100.

Racherla, P., Babb, J.S. and Keith, M.J. (2011), "Pay-what-you-want pricing for mobile applications: The effect of privacy assurances and social information", Conference for Information Systems Applied Research Proceedings, Vol. 4, No. 1833, pp. 1-13.

Regner, T. and Riener, G. (2012), "Voluntary payments, privacy and social pressure on the internet: A natural field experiment", DICE Discussion Paper, No. 82, Düsseldorf Institute for Competition Economics (DICE).

Riener, G. and Traxler, C. (2012), "Norms, moods, and free lunch: Longitudinal evidence on payments from a pay-what-you-want restaurant", Journal of Socio-Economics, Vol. 41, No. 4, pp. 476-483.

Ruffle, B.J. (1998), "More is better, but fair is fair: Tipping in dictator and ultimatum games", Games and Economic Behavior, Vol. 23, No. 2, pp. 247-265.

Santana, S. and. Morwitz, V.G. (2013), "We're in this together: How sellers, social values, and relationship norms influence consumer payments in pay-what-you-want contexts", Working Paper.

Schmidt, K.M., Spann, M. and Zeithammer, R. (2014), "Pay what you want as a marketing strategy in monopolistic and competitive markets", Management Science, Vol. 61, No. 6, pp. 1217-1236.

Schons, L.M., Rese, M., Wieseke, J., Rasmussen, W., Weber, D. and Strotmann, W.C. (2013), "there is nothing permanent except change: analyzing individual price dynamics in 'pay-what-you-want' situations”, Marketing Letters, Vol. 25, No. 1, pp. 25-36.

Slonim, R. and Garbarino, E. (2008), "Increases in trust and altruism from partner selection: Experimental evidence”, Experimental Economics, Vol. 11, No. 2, pp. 134-153.

Thomas, S. and Gierl, H. (2014), "Pay what you want: how to affect the price consumers are willing to pay", Proceedings of the 13th ICORIA: International Conference on Research in Advertising, June 26-28 2014, Amsterdam. 